\title{
Environmental assessment of waste transport and treatment: a case study
}

\author{
G. Ionescu \& P. Stefani \\ Department of Civil, Environmental and Mechanical Engineering, \\ University of Trento, Italy
}

\begin{abstract}
This research presents an in-depth environmental analysis of centralized versus distributed approaches on Municipal Solid Waste Management (MSWM) when selective collection (SC) reaches high rates. The goal of this study was to assess the major qualitative and quantitative emissions $\left(\mathrm{CO}, \mathrm{CO}_{2}, \mathrm{CH}_{4}, \mathrm{H}_{2} \mathrm{~S}, \mathrm{NO}_{\mathrm{x}}, \mathrm{SO}_{2}\right.$ and Volatile Organic Compounds) resulting from waste transport and treatment. The selection of the input data was made for a MSWM real case study for the Trentino region (Italy). Two main scenarios were developed and compared from an environmental point of view, for the organic fraction of waste (OFMSW) and residual waste (RMSW) treatment on site or at distance. The first scenario considers the OFMSW treatment in the studied region, using an anaerobic digestion process with biogas and compost production or its treatment at about $120 \mathrm{~km}$ from the place where the waste material was produced. In the second scenario, the RMSW is designated to an incineration plant that could be placed near the studied region or could be subject pre-treated for Solid Recovered Fuel (SRF) production that can be valorised in a plant located at about $170 \mathrm{~km}$. In order to evaluate the waste transport emissions, the COPERT computer program was used, considering the type of vehicle, fuel, load and speed. For waste treatment the emissions by type of pollutant are also assessed. In the results, it was highlighted that the transport environmental impact is higher in the biological treatment case. The results obtained can be used for the future development of MSW management strategies offering better environmental performances.
\end{abstract}

Keywords: anaerobic digestion, environmental impact, incineration, postcomposting, waste transport. 


\section{Introduction}

Lately, the Municipal Solid Waste Management (MSWM) strategies have been under significant scrutiny, mainly concentrating on treatment choice and its environmental impact. The MSW composition varies due to: geographical location, population habits and techno-economic potential existing. Even though the EU waste management regulations are drastic and landfill is the less preferred approach in any MSW strategy, it is still the most used one with $38 \%$ in the EU. The recycling option is directly proportional with elevated source separate waste rates that decrease the sorting costs. Looking over the Selective Collection (SC) rate, the year of entrance in the EU as member state does not guarantee high performances. In 2010, the SC overcame the 50\% target in only three countries, while five of them have still fewer than $10 \%$ [1].

Today, the most mature and robust technology for energy recovery is incineration, where in Europe more than $20 \%$ of the MSW stream is valorised [2, 3]. The main advantages of Solid Recovered Fuel (SRF) incineration over using MSW as fuel can be summed up in higher process efficiency, better quality of flue gases and significant reduction of heavy metals in the fly ashes. Both advantages are due to the composition of the incineration feedstock [4, 5]. From another point of view, the alteration of Residual Municipal Solid Waste (RMSW) characteristics might make it similar with SRF, strictly depending on the type of SC system adopted and its performances. The interest on biological treatments is growing in Europe due the high management cost associated with the processing of wet waste and the requirement to reduce the quantity of organic waste in the landfill fixed by the EU Landfill directive (99/31/EC) with $35 \%$ by 2016 considering the quantity produced in 1995 [6]. If the anaerobic digestion (AD) treatment is applied at a source segregated organic waste, and combined with digestate composting, it allows biogas production with energy recovery and nutrient soil replacement [7]. Research has shown that composting the MSW organic fraction, may improve the chemical and physical properties of the soil by increasing nutrient and water capacity, organic matter content, $\mathrm{pH}$, and caption exchange and that the compost effects depend on the dose used [8]. Considering a literature review, on different waste management strategies by single or multiple types of treatment and their environmental impacts, we can conclude that most of them are using the life cycle assessment methodology $[9,10]$. Generally, energetically and environmentally speaking, the best treatment for packaging materials is recycling and the best one for organic waste is anaerobic digestion [11]. Recent work, on an integrated MSW system has shown that even if the SC rate is 10 times higher in Central Europe regions, the global warming potential and acidification potential don't have significant fluctuations respect to the case were SC is lower [12]. Although road transport represents the main air pollution in urban areas [13] and consequent negative health effects, some limited work can be found on emissions from public waste transport by type of pollutant [14-17]. In this sector, most studies focus on GHG emissions, highlighting the environmental benefits of natural gas usage over 
diesel fuel, which can reduce the carbon footprint by $10-20 \%$ on a $\mathrm{CO}_{2}$ equivalent basis [18].

This research is an in-depth environmental analysis of centralized versus distributed approaches on MSWM when selective collection (SC) reaches high rates. The goal of this study is to assess the major qualitative and quantitative emissions by type of pollutant resulted from organic and Residual MSW (RMSW) transport and its treatment. The selection of the input data was made on MSWM real case study for Trentino region (Italy). Programming tools, specific datasets and average data from literature are used for the determination of carbon oxide $(\mathrm{CO})$, carbon dioxide $\left(\mathrm{CO}_{2}\right)$, methane $\left(\mathrm{CH}_{4}\right)$, hydrogen sulphide $\left(\mathrm{H}_{2} \mathrm{~S}\right)$, nitrogen oxides $\left(\mathrm{NO}_{\mathrm{x}}\right)$, sulphur oxides $\left(\mathrm{SO}_{\mathrm{x}}\right)$, ammonia $\left(\mathrm{NH}_{3}\right)$, and Volatile Organic Compounds (VOC) resulted from the management schemes developed in the study.

\section{Materials and methods}

\subsection{Waste stream and system boundaries}

The present work faces the problem of centralised versus distributed approaches of MSW management in Trentino region (Italy) were $270,165 \mathrm{t}_{\mathrm{MSW}} \mathrm{y}^{-1}$ are produced [1]. In the area studied, the overall $\mathrm{SC}$ rate is $74 \%$, classifying the waste stream as presented in. For the RMSW bulk, electronic equipment and hazardous materials were not reported because they presented concentration lower than $0.2 \%$.
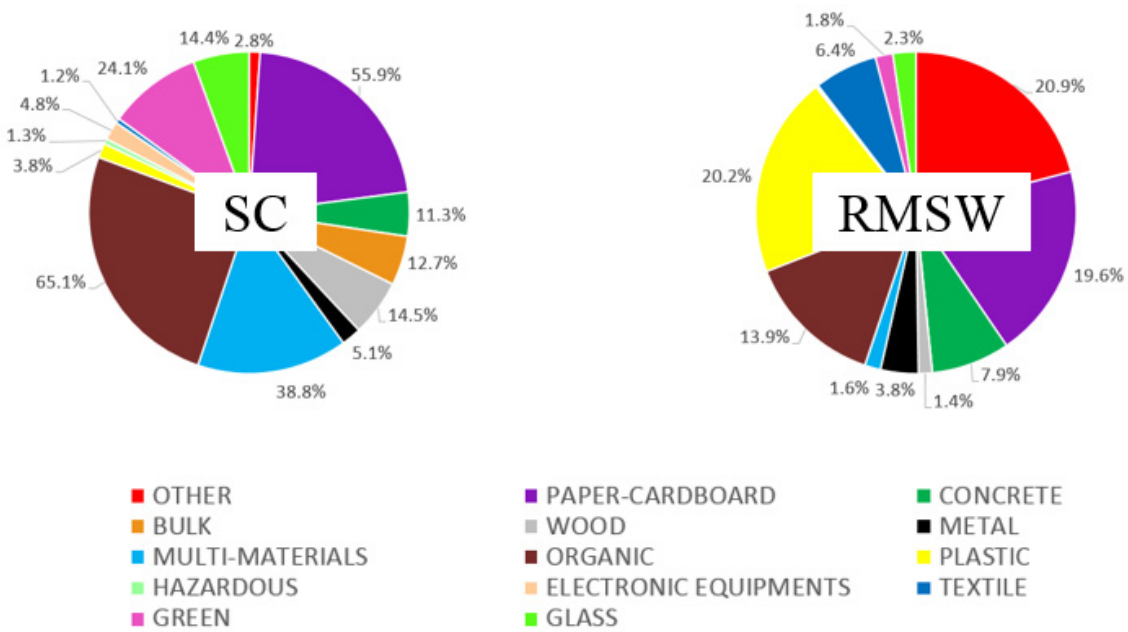

Figure 1: $\quad$ Composition of SC and RMSW in Trentino region (Italy). 
The source separated recyclable streams are sent to a materials recovery facility. Presently, the organic fraction of MSW (OFMSW) and green waste $(\mathrm{GW})$ are treated in two anaerobic digestion plants and a composting plant located in the region and close to it. The RMSW flow is sent to a landfill that is going to get exhausted. The last version of the local waste management plan takes into account the construction of an incinerator.

For the development of the waste management systems, all the assumptions will be described as clearly as possible to allow others to reproduce the analysis. In this research the organic waste is defined as the sum of OFMSW and GW. Two base main scenarios were developed for the OFMSW, GW (scenario A) and RMSW (scenario B) management pathways. In all the scenarios urban road or arterial highway were considered for the waste transport to the treatment facility. For each reference stream, the management system provides one centralised vision were the waste flow is treated in the Trentino region (scenarios A.1 and B.1), while the distributed one assumes to treat the organic waste (scenario A.2) at Isola della Scala (Verona, Italy) and the residual solid waste (scenario B.2) at Fusina (Venice, Italy). Using the same treatment assumptions, in scenario A, the organic waste is designed for biogas production and usage in a combined heat and power (CHP). In scenario B, the RMSW is destined for direct combustion in a future incineration plant at Trento (B.1) or SRF production and its recovery in an existing incineration plant at Fusina (B.2). For the latter scenario, three SRF transport lines are considered: B.2.1 the arterial highway A22-E45 (214 $\mathrm{km})$, B.2.2 the urban road SS-SP $47(170 \mathrm{~km})$ and B.2.3 possible future building of new arterial highway A31-North $(138 \mathrm{~km})$.

\subsection{Waste treatment plants and environmental assessment}

The design of the proposal cases of study is based on two treatment plants: anaerobic digestion of OFMSW and its post-composting with GW and RMSW incinerator.

\subsubsection{Anaerobic digestion and post-composting plant}

The difference between A.1 and A.2 cases study is on the road transport emissions. Indeed, the scenario A.1 contemplates only the emissions from the treatment plant situated in Trento and the A.2 scenario, adds the road emissions due the transport of the organic waste from Trento to Isola della Scala $(118 \mathrm{~km})$. The estimation of the volume material transportation was made assuming the density values $250 \mathrm{~kg} \mathrm{~m}^{-3}$ and $150 \mathrm{~kg} \mathrm{~m}^{-3}$ respectively, for OFMSW and GW [19].

Scenario A concentrates on organic waste treatment considering the following treatment chain:

- On the strength of a real facility, it was assumed an OFMSW pre-treatment made up by a mechanical pre-treatment step, consisting of a garbage bag opener machine, shredding and sieving. In this step, $2 \%$ of the input mass was considered rejected waste.

- The modeling of the AD process was carried out by evaluating mass and energy balances of some of the most recent studies on plants operating in 
Italy and Europe. As a result, a wet process was selected with an estimated total biogas production of $110 \mathrm{~m}^{3} \mathrm{t}_{\text {OFMSW }}{ }^{-1}$ [20]. The biogas produced is sent to an internal combustion engine for combined heat and power (CHP) production.

- In the aerobic unit process the digestate was mixed with $\mathrm{GW}$, derived from $\mathrm{SC}$, to improve the biological process. It was hypothesized that the exhausted air from the aerobic treatment was not sent to the gas flue cleaning system (e.g. biofilter) but it was added up at the engine's air. Therefore, there is a unique point emission in this treatment plant that is the exhausted gas from CHP. The values present in the European Commission work were taken as reference in order to characterize emissions resulted from the process [21].

\subsubsection{Incinerator plant}

For scenario B, two options were considered for the RMSW treatment:

- In scenario B.1, the RMSW as received is sent directly in a future incineration plant at Trento. The present choice was considered, due to the low quantity of inert material (e.g. metal and glass) in the RMSW. The Lower Heating Value (LHV) was calculated considering the waste composition by fraction (Figure 1).

- In scenario B.2 the RMSW is first sent to a shredder and compactor equipment in order to homogenise the mass, to increase its density and thus reduce the number of trips for the transport of material at Fusina facility.

- The determination of the material density after its pre-treatment was done considering the data reported by [19]; as for the shredding was utilized a density increase efficiency of $30 \%$ respect the raw material [22] and regarding the compactor was assumed a final compacted $\mathrm{SRF}_{\text {final }}$ density value of $700 \mathrm{~kg} \mathrm{~m}^{-3}$ [23].

\subsubsection{Environmental assessment}

The environmental impact of these treatments was valuated considering the most important pollution parameters. In the pollution indicator per tonne of input waste was depicted.

Table 1: Environmental parameters adopted for $\mathrm{AD}$ and post-composting plant and incinerator plant $\left(\mathrm{g} \mathrm{t}_{\mathrm{ww}}{ }^{-1}\right)$.

\begin{tabular}{|l|l|l|l|l|l|l|l|l|l|}
\hline (g tww-1) & $\mathrm{CO} 2 \mathrm{eq}$ & $\begin{array}{l}\mathrm{CO} 2 \\
\text { fossil }\end{array}$ & $\mathrm{NOx}$ & $\mathrm{CO}$ & $\mathrm{VOC}$ & $\mathrm{NH} 3$ & $\mathrm{SOx}$ & $\mathrm{CH} 4$ & $\mathrm{~N} 2 \mathrm{O}$ \\
\hline $\begin{array}{l}\text { AD and } \\
\text { composting } \\
\text { plant }\end{array}$ & $\begin{array}{l}\text { ISO } \\
14040: 2006\end{array}$ & 0 & 10 & 658.0 & $100.2 \mathrm{a}$ & n.d. & 394.8 & 263.2 & 526.4 \\
\hline $\begin{array}{l}\text { Incinerator } \\
\text { plant }\end{array}$ & 590000 & $452000 \mathrm{~b}$ & 230 & 40 & 3 & 4 & 1 & n.d. & n.d. \\
\hline
\end{tabular}

${ }^{a}$ Value was obtained from Italian Legislative Decree 152/2006.

${ }^{\mathrm{b}}$ Turconi et. al. 2011. 
The AD and composting parameters are in agreement with [21] and incinerator indicators with a real facility in Milan [24]. No data were found for $\mathrm{NH}_{3}$ and $\mathrm{CH}_{4}, \mathrm{~N}_{2} \mathrm{O}$ respectively, for the anaerobic/aerobic and combustion process.

Among the assumptions made, the $\mathrm{CO}_{2}$ is not taken into account as greenhouse gas during the biological treatment, as it comes from biogenic source and it might be considered climate-neutral. In this case the $\mathrm{CO}_{2 \mathrm{eq}}$ resulted from the biogas combustion was calculated considering the ISO 14040:2006 standard. For the determination of the carbon footprint the $\mathrm{CH}_{4}$ and $\mathrm{N}_{2} \mathrm{O}$ quantities and their potential cumulative effect into the atmosphere considering the 100 -year time horizon were used.

\subsection{Emissions from road transport}

One of the most used road emissions transport in the European Union, is COPERT 4. This is an algorithm developed by European Environment Agency (EEA) for the calculation of air pollution emissions from road transport. COPERT allows estimating emissions of the major air pollution: $\mathrm{CO}, \mathrm{CO}_{2}, \mathrm{CH}_{4}$, $\mathrm{NO}_{\mathrm{x}}$, lead $(\mathrm{Pb})$, particulate matter $(\mathrm{PM}), \mathrm{SO}_{2}$, volatile organic compounds (VOCs), and other metals. The algorithm contemplates the emissions produced during stabilized engine operation (hot emissions) and emissions that occur during engine start (cold-start and warming-up effect), since the catalyst does not work at low temperature. Moreover, this algorithm takes into account five microclasses of vehicles: passenger cars, light duty vehicles (LDVs), heavy duty vehicles (HDVs), cycles and motorcycles. Every micro-classes is characterized by capacity (or mass for HDVs), fuel type and the European emissions standard vehicles, starting from pre-EURO I to EURO VI [25].

In the present study, COPERT 4 was used for the evaluation of the emissions coming from waste transport. For all the scenarios, the assumption made for the assessments of road transport emissions impact are summed up in the following:

- Mean atmosphere temperature $15^{\circ} \mathrm{C}$;

- 2009 fuel characteristic;

- Heavy Duty Truck (HDT) articulated Euro V (2008 standard), payload $36,800 \mathrm{~kg}$, useful volume $93 \mathrm{~m}^{3}$ for SRF transport and $84 \mathrm{~m}^{3}$ for OFMSW-GW, vehicle load 50\% for SRF transport and 36\% for OFMSWGW;

- Mean speed road: $80 \mathrm{~km} \mathrm{~h}^{-1}$ highway, $70 \mathrm{~km} \mathrm{~h}^{-1}$ rural, $50 \mathrm{~km} \mathrm{~h}^{-1}$ urban;

- Density material: $\rho_{\text {OFMSW_GW }}=211.8 \mathrm{~kg} \mathrm{~m}^{-3}, \rho_{\mathrm{SRF}_{-} \text {final }}=700 \mathrm{~kg} \mathrm{~m}^{-3}$.

\section{Results}

The scenarios modelling and simulation results are presented in Figure 2. For each step, the mass balance is calculated, along with the overall emissions considering the main waste treatments and transport.

The shredding and compaction step are very important in waste transport not only from the environmental perspective but also from the economical one. To 
save money it is important to apply these pre-treatments on a commingled waste stream that reduces its particle size up to 3-4 times and therefore the volume of material prior to transport. It is resulted that although the RMSW mass input in the system, is slightly lower $(5 \%)$ respect to the organic waste one, the SRF volume that has to be transported is considerable reduced due to its increased density. Considering the HDTs round trip, a number of 14 runs are necessary for SRF transport and 22 for the organic waste.

In scenario $\mathrm{A}$, the biogas average production was estimated to be $5,433,518 \mathrm{~m}^{3} \mathrm{y}^{-1}$. Biogas is composed by $66 \%$ methane, the rest being represented by $\mathrm{CO}_{2}$ and other components. The low heating value (LHV) of the biogas produced is round $23.9 \mathrm{MJ} \mathrm{m}^{3}$ biogas. The compost mass is round $30 \%$ [20] from the OFMSW and can be used as substitute for peat and mineral fertilizers. In scenario B.1, RMSW contains oxidizable materials (especially carbon and hydrogen) which can free considerable energy. Due to the low quantity of inert materials (e.g. metals, glass) in the stream composition (Fig.1) the LHV of the

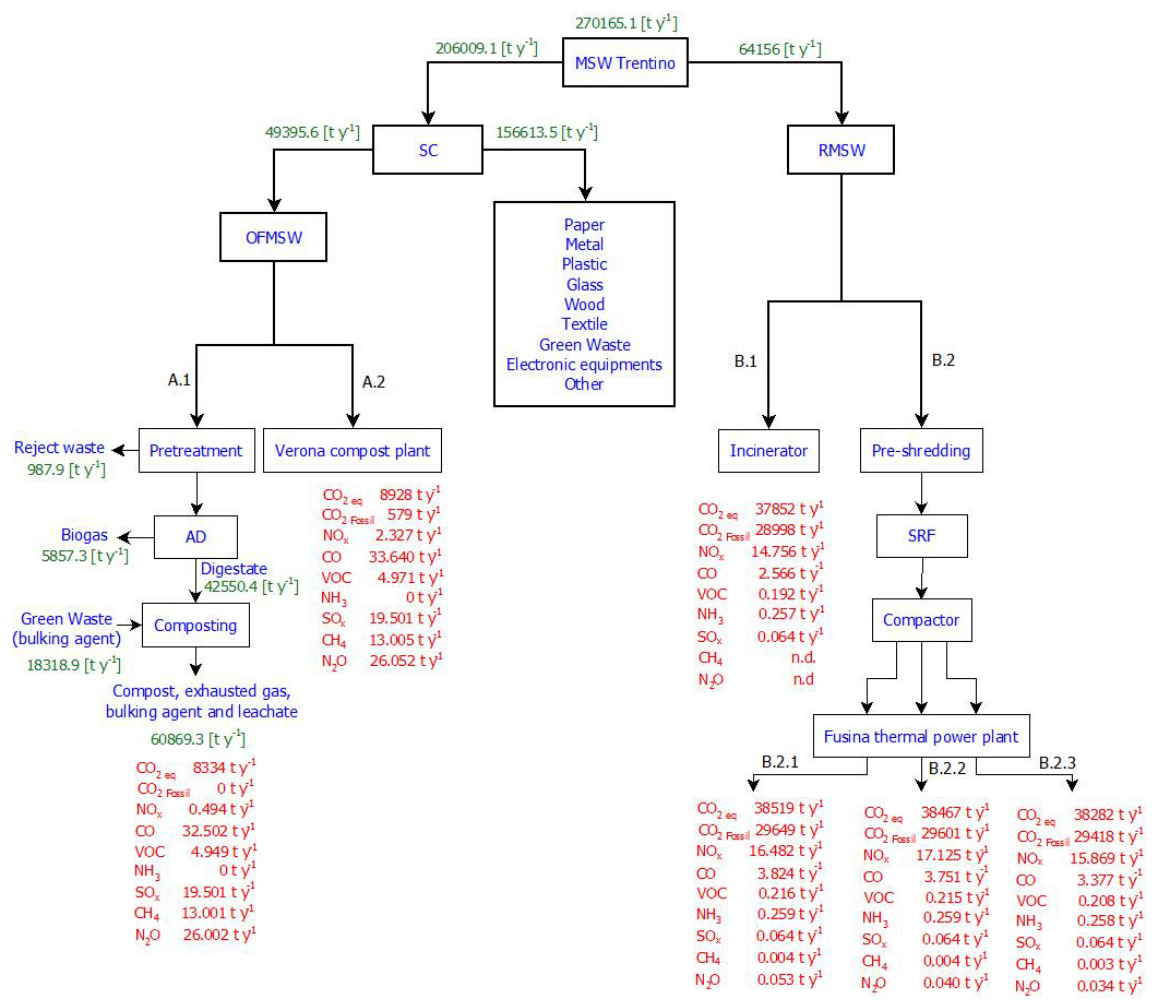

Figure 2: Flowchart, mass balance and emissions value of Trentino case study. 
RMSW is about $13,250 \mathrm{~kJ} \mathrm{~kg}_{\mathrm{ww}}{ }^{-1}$. At this point, the waste is sent directly to the hypothetical future incineration plant in Trento with no pre-treatment.

In scenario B.2, the mechanical pre-treatment is applied in order to reduce the volume that has to be transported to the existing Fusina thermal power plant and overcome the possible technical damages of the feed line. The SRF energetic potential is almost the same with the RMSW one. With this regard, according to the Italian legislation, the SRF is considered a product/end-of-waste and not a waste, and it is named combustible SRF.

In order to assess the overall transport emissions resulted from the main scenarios (A and $\mathrm{B}$ ) the $\beta$ ratio was defined. The $\beta$ parameter was expressed as the ratio between the transport and treatment emissions, by type of pollutant.

As can be seen in figure 2, the transport impact has more influence in the AD and post-composting facility than incinerator plant. Indeed, the transport emission is influential for $\beta=7 \%$ in $\mathrm{CO}_{2 \text { eq }}$ for the A scenario, while less $2 \%$ for the others. This is due at the high value of the $\mathrm{CO}_{2 \mathrm{eq}}$ incinerator facility and the low value for the biological treatment. Furthermore, even the $\mathrm{NO}_{\mathrm{x}}$ transport impact is about 4 times higher than the anaerobic/aerobic treatment and between $\beta$ range $7.5 \%$ and $16.1 \%$ in the $B$ scenarios.

Considering the B.2.1 and B.2.2 scenarios, it highlights as the $\beta \mathrm{CO}_{2 \mathrm{eq}}$ parameter is almost equal (respectively $\beta_{\mathrm{CO} 2 \mathrm{eq}}=1.8 \%$ and $\beta_{\mathrm{CO} 2 \mathrm{eq}}=1.6 \%$ ), even if the transport lines are different. The B.2.1 scenario provides a pathway of 214 $\mathrm{km}$ in arterial highway; on the other hand, the B.2.2 scenario foresees $170 \mathrm{~km}$ in urban road. It's quickly observed that B.2.3 scenario presents less highway kilometers than B.2.1 but more than B.2.2 and the transport emissions is lower $\left(\beta_{\mathrm{CO} 2 \mathrm{eq}}=1.1 \%\right)$. The comparison between A.1 and A.2, it notes no relevant differences in terms of $\mathrm{VOC}$ and $\mathrm{CO}$, but only in the $\mathrm{NO}_{\mathrm{x}}$ and $\mathrm{CO}_{2 \mathrm{eq}}$ as above mentioned.

In sum, it should be aware that not on the distance and implicit the fuel consumption are factors that define the emissions but also the: average speed, vehicle load and road gradient.

\section{Conclusions and outlooks}

The basic methodology and assumptions applied in the present study may also be used at more extensive studies or be considered in waste management decision tools in areas with similar input data.

It is clear that the magnitude of the environmental impacts produced by the waste transportation service increases with the size of the served community.

In the results, it was highlighted that the transport environmental impact is higher in the biological treatment case. Furthermore, the RMSW/SRF quantity is typical for a small incinerator plant with an input flow of less than $192 \mathrm{t}_{\mathrm{RMSW} / \mathrm{SRF}} \mathrm{d}^{-1}$. If the quantity of material that has to be incinerated increases, the pollutant emissions coming from transport have less influence on the overall environmental analysis. Even though the evaluations make above consider a difference in the transport length (A.2: $118 \mathrm{~km}$, B.2: $214 \mathrm{~km}, 170 \mathrm{~km}$ and 
$138 \mathrm{~km}$ ), if the comparison was made with the same length, the impact of transport emissions would be higher.

Still, the combined-heat and power incineration plants using RMSW or SRF might offer a slightly positive environmental impact compared to energy generation from fossil fuels.

\section{References}

[1] Rada, E.C., Effects of MSW selective collection on waste-to-energy strategies. WIT Transactions on Ecology and the Environment, 176, pp. 215-223, 2013.

[2] Turconi, R., Butera, S., Boldrin, A., Grosso, M., Rigamonti, L., Astrup, T., Life cycle assessment of waste incinerator in Denmark and Italy using two LCA models. Waste Management \& Research, 29(10), pp. 78-90, 2011.

[3] Ragazzi, M., Torreta, V., Ionescu, G., Istrate, I.A., Maintenance strategies and local impact of MSW incinerators. WIT Transactions on Ecology and the Environment, 176, pp. 235-244, 2013.

[4] Montejo, C., Costa, C., Ramos, P., Márquez, M. C., Analysis and comparison of municipal solid waste and reject fraction as fuels for incineration plants. Applied Thermal engineering, 31(13), pp. 2135-2140, 2011.

[5] Rada, E.C., Andreottola, G., RDF/SRF: Which perspective for its future in the EU. Waste Management, 32(6), pp. 1059-1060, 2012.

[6] Rada, E.C., Ragazzi, M., Selective collection as a pretreatment for indirect solid recovered fuel generation, Waste Management 34(2), 291-297, 2014.

[7] Banks, C. J., Chesshire, M., Heaven, S., Arnold, R., Anaerobic digestion of source-segregated domestic food waste: Performance assessment by mass and energy balance. Bioresource Technology, 102(2), pp. 612-620, 2011.

[8] Tambone, F., Scaglia, B., D’Imporzano, G., Schievano, A., Orzi, V., Salati, S., Adani, F., Assessing amendment and fertilizing properties of digestates from anaerobic digestion through a comparative study with digested sludge and compost. Chemosphere, 81(5), pp. 577-583, 2010.

[9] Fruergaard, T., Astrup, T., Optimal utilization of waste-to-energy in an LCA perspective. Waste Management, 31(3), pp. 572-582, 2011.

[10] Bakshi, B.R., The path to a sustainable chemical industry: progress and problems. Current Opinion in Chemical Engineering, 1(1), pp. 64-68, 2011.

[11] Saer, A., Lansing, S., Davitt, N. H., Graves, R. E., Life cycle assessment of a food waste composting system: environmental impact hotspots. Journal of Cleaner Production, 52, pp. 234-244, 2013.

[12] Ionescu, G., Rada, E.C., Ragazzi, M., Mărculescu, C., Badea, A., Apostol, T., Integrated Municipal Solid Waste scenario model using advanced pretreatment and waste to energy processes. Energy Conversion and Management, 76, pp. 1083-1092, 2013. 
[13] Torretta V., Raboni M., Copelli S., Rada E.C., Ragazzi M., Ionescu G., Apostol T., Badea A., Application of strategies for particulate matter reduction in urban areas: an Italian case. U.P.B. Sci. Bull. Series D, 75(4), pp. 221-228, 2013.

[14] Ciuta S., Schiavon M., Chistè A., Ragazzi M., Rada E.C., Tubino M., Badea A., Apostol T., Role of feedstock transport in the balance of primary PM emissions in two case-studies: RMSW incineration vs. sintering plant. UPB Sci. Bull. Serie D Mechan Eng., 74(1), pp. 211-218, 2012.

[15] Torretta V., Rada E.C., Panaitescu V.N., Apostol T., Some considerations on particulate generated by traffic. Sci Bull. Mechan Eng. serie D, 74(4), pp. 141-148, 2012.

[16] Ionescu, G., Zardi, D., Tirler, W., Rada E.C., Ragazzi, M. A critical analysis of emissions and atmospheric dispersion of pollutants from plants for the treatment of residual municipal solid waste. UPB Sci. Bull. Mechan Eng Series D, 74 (4), pp. 227-240, 2012.

[17] Schiavon, M., Antonacci, G., Rada, E.C., Ragazzi, M., Zardi, D., Modelling Human Exposure to Air Pollutants in an Urban Area, Revista de Chimie, 65 (1), pp. 62-65, 2014.

[18] Graham, L. A., Rideout, G., Rosenblatt, D., Hendren, J., Greenhouse gas emissions from heavy-duty vehicles. Atmosphere Environment, 42(19), pp. 4665-4681, 2008.

[19] Chandrappa, R., Das, D.B., Waste quantities and characteristics (Chapter 2). Solid Waste Management, Environmental Science and Engineering, Springer-Verlag: Berlin and Heidelberg, pp. 47-63, 2012.

[20] Pognani, M., Barrena, R., Font, X., Scaglia, B., Adani, F., Sánchez, A., Monitoring the organic matter properties in a combined anarobic/aerobic full-scale municipal source-separated waste treatment plant. Bioresource technology, 101(17), pp. 6873-6877, 2010.

[21] Economic analysis of options for managing biodegradable municipal waste; ECOTEC Research and Consulting Limited (ECOTEC), in association with Eunomia Research \& Consulting, HDRA Consultants Ltd (UK), Zentrum für rationelle Energieanwendung and Umwelt $\mathrm{GmbH}$ (ZREU), Scuola Agraria del Parco di Monza and LDK Consultants http://ec.europa.eu/environment/waste/compost/pubs.htm

[22] Fitzgerald, G.C., Themelis, N.J., Technical and economic impacts of preshredding the MSW feed to moving grate WtE boilers, Proc. of the $17^{\text {th }}$ Annual North American Waste-to-Energy Conference, Chantilly, Virginia, USA, pp. 1-7, 2009.

[23] Yandong, L., Henry, L., Ou, Z., High-pressure compaction of municipal solid waste to form densified fuel. Fuel processing technology, 74(2), pp. 81-91, 2001.

[24] AMSA, Incinerator Silla 2 - Environmental bulletin. http://www.comune. milano.it/portale/wps/portal/CDM?WCM_GLOBAL_CONTEXT=/wps/w $\mathrm{cm} /$ connect/ContentLibrary/Ho\%20bisogno\%20di/Ho\%20bisogno\%20di/I ncentiviIniziativeAmbiente_Emergenze $\% 20$ Ambientali\&categId $=$ com.ib 
m.workplace.wcm.api.WCM_Category/IT_CAT_Bisogni_09/6989610044 6e01acba81bbd36d110d8a/PUBBLISHED\&categ=IT_CAT_Bisogni_09\&t ype $=$ content\&sizeStyle $=$ defautSize \&colorStyle $=$ defautColor.

[25] Ionescu, G., Schiavon, M., Rada, E.C., Ragazzi, M., Stroe, C., Cioranu, I., Panaitescu, V., Stefani, P., Evolution of the emission performances of MSW collection trucks. Proc. of the $14^{\text {th }}$ International waste management and landfill symposium, Padova: CISA, Environmental Sanitary Engineering Centre, S. Margherita di Pula (CA), pp. 1-9, 2013. 